
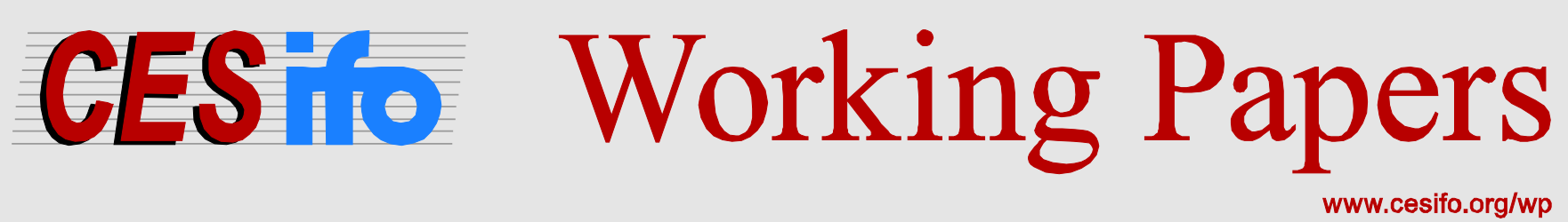

\title{
Welfare Benefit Reforms and Employment
}

\author{
Marta Aloi \\ Teresa Lloyd-Braga \\ Manuel Leite-Monteiro
}

\author{
CESIFO WORKING PAPER No. 6403 \\ CATEgory 6: Fiscal Policy, Macroeconomics and GROWTH \\ MARCH 2017
}

An electronic version of the paper may be downloaded

- from the SSRN website:

- from the RePEc website:

- from the CESifo website:

www.SSRN.com

www.RePEc.org

www.CESifo-group.org/wp 


\title{
Welfare Benefit Reforms and Employment
}

\begin{abstract}
We consider an economy characterised by involuntary unemployment among low skilled workers, and investigate the implications for employment and income of welfare schemes often advocated as less distortionary. We show that reducing unemployment benefits in favour of income subsidies (social benefits) reduces employment in general equilibrium and also the income of low skilled workers, for not too high distortions in the labour market. Furthermore, it leads to a higher tax burden and a welfare deterioration. To support employment, we suggest that systems grounded in contribution-based unemployment insurance schemes are to be preferred and strengthened.
\end{abstract}

JEL-Codes: H200, I380, J650.

Keywords: unemployment benefits, social benefits, taxes, unions, employment.

\author{
Marta Aloi \\ School of Economics \\ University of Nottingham \\ University Park \\ United Kingdom - NG7 2RD Nottingham \\ marta.aloi@nottingham.ac.uk
}

Teresa Lloyd-Braga

Católica Lisbon School of Business and

Economics / Universidade Católica

Portuguesa, Palma de Cima

Portugal -1649-023 Lisbon

tlb@ucp.pt
Manuel Leite-Monteiro

Teresa Lloyd-Braga

Católica Lisbon School of Business and Economics / Universidade Católica

Portuguesa, Palma de Cima

Portugal -1649-023 Lisbon

mlm@ucp.pt 


\section{Introduction}

Welfare support is typically made up of an insurance component (unemployment benefits) and a redistributive component (means-tested benefits). Which of these elements prevail differs across countries. For instance, Denmark has a generous voluntary unemployment insurance programme, which operates in combination with a less generous, means-tested, social assistance programme (see Parsons et al. 2015). The United Kingdom, in contrast, has relatively modest unemployment insurance benefits and more sizable means-tested income assistance programmes. Although welfare systems may differ considerably across OECD countries, one common feature is that most of these countries have undertaken, over the years, various welfare reforms.

Notably, in most OECD countries the largest number of policy changes in recent years have concerned unemployment insurance benefits. European governments, in particular, have tended to reduce benefit generosity (amounts or duration) since the early 2000s. Compared with unemployment insurance, changes to unemployment assistance rules have been fewer and smaller. However, employment-conditional benefits (or "in-work" income benefits) have expanded substantially since the 1980s in some countries, particularly in the UK. ${ }^{1}$ The evolution of the welfare system in the UK offers a case in point. Established in the late 1940s, after the publication of the Beveridge report (1942), the UK welfare system contemplated a very minimal use of means-tested benefits; however, over the years, it has evolved as the opposite of what Beveridge envisaged, with the role of the insurance principle declining and the role of means-testing growing. This drift away from the original conception of the modern welfare state is even more striking when one looks at recent reforms introduced in the UK, aimed at curbing even further the role of unemployment insurance in favour of universal credit. $^{2}$

The consensus seems to be that decreasing unemployment subsidies in favour of an income subsidy (social benefit) is desirable in that it reduces the disincentive effects of unemployment benefits on labour supply and, at the same time, it sustains the income of low skilled employed workers. ${ }^{3}$ Notably, the widely debated idea of

\footnotetext{
${ }^{1}$ See, p. 24 of OECD (2013) where it is also stated: "UK in-work benefits were significantly more generous than the Earned Income Tax Credit in the US [...] with per-family expenditures on average about four times as high in the early 2000s."

${ }^{2}$ In March 2013 the UK government has introduced a radical package of welfare reforms. The largest structural change planned is the introduction of universal credit (UC). The UC is going to replace six existing benefits, including Jobseeker's Allowance, with a single monthly payment. It is meant to encourage unemployed people to move from claiming unemployment benefits into paid work. For those already in paid work, UC is meant to increase labour market attachment.

${ }^{3}$ There is a wide variety of social assistance subsidies used in different countries and across different welfare systems. For the purpose of our analysis, it is convenient to bundle all different types of social assistance benefits in one entity that we call social benefits, to which all low skilled workers (employed and unemployed) are entitled. Incidentally, many countries are now moving to much simplified systems where different transfers aimed at supporting income are bundled in one single benefit. The introduction of UC in the UK, previously mentioned, is one example.
} 
shifting from unemployment insurance to a guaranteed minimum income also fits into this narrative. ${ }^{4}$

In the present paper, we explore the implications of such a shift and argue that, in the spirit of Beveridge, workers (and the economy as a whole) would be better off with a larger role for unemployment insurance benefits and a lesser role for social benefits.

We show that, in a world characterised by labour market distortions and involuntary unemployment among low skilled workers, curbing unemployment insurance in favour of social benefits has detrimental effects on both employment and income.

In essence, reducing unemployment insurance benefits in favour of social benefits is detrimental because, in general equilibrium, employment declines and the tax burden for employed workers increases. The key to understanding this result is to distinguish between partial and general equilibrium effects.

Assume that an unemployment insurance scheme is in place, whereby unemployed workers receive a fixed flat benefit financed by a premium (tax) paid by employed low skilled workers. Assume also that all low skilled workers (employed and unemployed) receive a social benefit financed by a tax on the wage. The latter is set as a mark-up over the reservation wage (due to unions), and the reservation wage is itself increasing in the unemployment benefit, the unemployment insurance premium and the tax rate levied to finance the social benefit. In the labour market, the social benefit tax and the unemployment insurance premium are taken as given in partial equilibrium. Hence, the only effect of a decrease in the unemployment benefit is to decrease the reservation wage which results in higher employment. The social benefit, by design, does not directly affect the reservation wage in partial equilibrium and, therefore, has no effect on employment. Partial equilibrium results, therefore, seem to support the view that reducing the unemployment insurance component in favour of the social assistance component is beneficial for employment.

In general equilibrium, however, the tax burden and the reservation wage react to changes in employment through the balanced budget requirements of the benefit schemes, potentially reversing the partial equilibrium effects. We show that, if the elasticity of substitution between low skilled and high skilled labour is high enough, an increase in unemployment insurance, and/or in social benefits, is associated with a decrease in the reservation wage and an increase in the employment level of low skilled. Intuitively, because the premium required to balance the unemployment insurance budget constraint, and the tax needed to balance the social benefit budget constraint, both decrease with employment, workers are more inclined to work more at lower wages (gross of taxes), to which firms respond by increasing labour demand. The working of this mechanism mirror the working of a market/fiscal externality, in that the unemployment insurance premium and the benefit tax are taken as

\footnotetext{
${ }^{4}$ The argument is (see, e.g., Atkinson 1995) that, by conferring a flat basic-income payment, poverty traps would be eliminated. And, since the benefit would not phase out, there would be no reduced incentive to seek additional work hours or income.
} 
given at the private decision level over employment, but influence labour market conditions and the (general) equilibrium level of employment via the balancedbudget requirements.

Moreover, employment responds more to changes in the unemployment insurance benefit since, ceteris paribus, the general equilibrium reservation wage is more sensitive to changes in the unemployment insurance benefit than to changes in the social benefit. ${ }^{5}$ As a result, replacing a lower unemployment insurance benefit with a higher social benefit bring about a net decrease in the employment level.

Furthermore, since the tax burden is decreasing in employment, it is more costly for employed workers to finance an increase in social benefits rather than an increase in unemployment insurance. This observation motivates our next result, where we show that, if the unemployment rate is low and the union bargaining power is not high, per capita net income of low skilled employed workers is likely to increase more with an increase in unemployment insurance than with an identical increase in social benefits. Therefore, a policy of lower unemployment benefits in favour of more social benefits has also a detrimental effect on income levels. In terms of social welfare, we show that the opposite policy, namely a decrease in the social benefit coupled with an identical increase in the unemployment benefit, is welfare improving for a wide class of social welfare functions.

From an empirical perspective, there is evidence that countries with more generous unemployment insurance benefits appear to be associated with increasing employment. Tatsiramos (2009) studies the effects of unemployment benefits on unemployment and employment duration in Europe and finds that the general equilibrium effect (or indirect effect) of unemployment insurance on employment is positive for countries with more generous benefits. Howell and Rehm (2009) provide similar evidence for OECD countries. More recently, Lalive et al. (2015) specifically tackle the issue of quantifying the relative magnitude of partial (micro) and general (macro) equilibrium effects of variations in benefits in the labour market. Using the Regional Extension Benefit Program implemented in Austria between 1988 and 1993, they find a significant positive wedge between micro and macro effects when changing unemployment insurance for the whole labour market, indicating that the optimal level of unemployment insurance will be larger than suggested by the partial equilibrium level. ${ }^{6}$ Lalive et al. (2015) rationalise their

\footnotetext{
${ }^{5}$ As discussed later on in the paper (p.11), this is a consequence of the wage being set above the reservation wage and of the social benefit being paid to both unemployed and employed. Intuitively, for a given level of employment, the higher the wage mark up (i.e., the higher union bargaining power) the higher the wage and the lower the implicit tax rates paid to finance the benefits. The reduction in the implicit tax associated with higher union bargaining power is larger for the social benefit, as the latter is received by both unemployed and employed. The fact that, for a given level of employment, the social benefit implicit tax rate is lighter the higher the union bargaining power implies, in turn, a muter response of the reservation wage to increases in the social benefit compared to increases in the unemployment insurance benefit.

${ }^{6}$ Interestingly, in Austria almost all workers are covered by collective agreements which take place at the sectoral (or the occupational) level (p. 3570, Lalive et al. 2015).
} 
result by appealing to search externalities, implying that "an increase in unemployment insurance generosity, by decreasing aggregate search effort, increases the probability of finding a job per unit of search effort" (p. 3568). Although in our framework we do not have search effects, we identify a general equilibrium adjustment, overlooked by Lalive et al. (2015) that, as hinted above, can also work as a market/fiscal externality.

From a theory perspective, in recent years, there has been a proliferation of models with unemployment insurance and labour market frictions focusing, mainly, on the issues of optimal unemployment insurance design and optimal time-path of unemployment benefits. Shimer and Werning (2007, 2008), in particular, distinguish between insurance and liquidity roles of unemployment benefits and find that benefits should be constant or increasing over time. Similarly, Chetty (2008) distinguishes between a liquidity effect and a moral hazard effect and estimate that, in the United States, the former dominates the latter, implying a welfare gain associated with higher unemployment insurance. These works, however, are limited to a partial equilibrium analysis. In the literature on timing of unemployment compensation, Shavell and Weiss (1979) first, and many others afterwards, argued that a declining time sequence of unemployment compensation is desirable because it prompts greater search effort. This conclusion has been challenged in subsequent work by Cahuc and Lehmann (2000) arguing that in general equilibrium declining unemployment benefits may actually increase unemployment and decrease welfare. To assess general equilibrium effects, though, they need to resort to calibration exercises.

Our paper differs from the rest of the literature in several dimensions. First, rather than focusing on the design of unemployment benefits, we study the implications for equilibrium employment and income of welfare schemes often advocated as less distortionary, which, to the best of our knowledge, is new. ${ }^{7}$ Second and more importantly, we obtain closed form solutions and show analytically that such welfare schemes may lead to unintended effects, notably, a fall in employment and a welfare deterioration. From a policy perspective, our results are at odds with the consensus that reforms to welfare should emphasise more the redistributive component at the expenses of the insurance component of unemployment benefits. Instead, our analysis suggests that systems grounded in contribution-based unemployment insurance schemes are to be supported and strengthened. The notion that the redistributive component (through social benefits) is superior to the insurance component rests on the idea that unemployment benefits exert undesirable effects on the reserva-

\footnotetext{
${ }^{7}$ There is a fairly substantial literature studying the effects of replacing unemployment insurance with other instruments aimed at reducing the workers reservation wage (e.g. tax credits). These are revenue-neutral reforms and are, typically, assessed in partial equilibrium (see, e.g., Blundell, 2001). We, in contrast, consider a tax-financed increase in a flat-income payment (social benefit) and a reduction in unemployment insurance. A policy which is not revenue-neutral, since wages, employment and, thereby, taxes are endogenous in general equilibrium. And, emphasise a potentially important channel of equilibrium adjustment through which lower employment and lower worker welfare are obtained.
} 
tion wage (and the labour supply), while social benefits do not. However, once the general equilibrium effects, due to the need of financing both benefits, are taken into account such a notion turns on its head. Namely, it is because the reservation wage is more sensitive to the unemployment benefit than to the social benefit that explains why it is preferable to strengthen the insurance component of welfare support to the unemployed.

The remainder of the paper is organised as follows. In the next section we describe the model and look at partial and general equilibrium outcomes. In Section 3 we evaluate the effect on employment, income and welfare of unemployment insurance against social benefits. Section 4 considers a few extensions to the model to further support our main results. Section 5 concludes.

\section{The model}

We consider an economy where output is produced under perfect competition, using high skilled and low skilled labour, and where the labour market is segmented. The economy is populated by $N_{L}$ low skilled workers and $N_{H}$ skilled workers, each exogenously supplying one unit of their respective labour service. A single good $y$, taken as the numeraire, is produced by $M$ identical firms, each using skilled labour $h$, and low skilled labour $l$, under a constant returns technology $y=A F(h, l) \equiv A l f(x)$, with $x \equiv h / l$ denoting skill intensity. ${ }^{8}$

Assumption 1 The intensive production function $f(x)$ is a real, continuous function for $x \geq 0$, positively valued and differentiable as many times as needed for $x>0$, with $f^{\prime}(x)>0, f^{\prime \prime}(x)<0$ and $f(x)-f^{\prime}(x) x>0$. The elasticity of the intensive production function is denoted by $s(x) \in(0,1)$ and $\sigma(x)>1$ represents the elasticity of substitution between high and low skilled labour, with

$$
\begin{gathered}
s(x) \equiv \frac{f^{\prime}(x) x}{f(x)} \\
-\frac{1-s(x)}{\sigma(x)} \equiv \frac{f^{\prime \prime}(x) x}{f^{\prime}(x)} .
\end{gathered}
$$

We impose $\sigma>1$ in keeping with empirical evidence. ${ }^{9}$

The skilled labour market is perfectly competitive with full employment, while the market for low skilled labour is characterised by unemployment and wage rigidities. Namely, wage and employment levels are the outcome of efficient bargaining

\footnotetext{
${ }^{8}$ We consider only two skill levels: high skilled referring to workers with more than high school education levels, and low skilled referring to all other workers with high school, or lower, education levels. This classification follows Card (2009), who shows that, for the United States, workers with primary education are perfect substitutes for those with a high school education.

${ }^{9}$ This is the standard assumption in the literature. See, for instance, Acemoglou $(2002,2003)$. Katz and Murphy (1992), using data for the period 1963-1987, report an empirical estimate for this elasticity of 1.41. Autor et al. (2008) extended that analysis to 2005 and find a value of 1.61.
} 
between unions and firms. As it will be shown below, low skilled workers receive a wage $w^{L}$ which is set as a mark-up over the reservation wage. High skilled workers, on the other hand, are rewarded according to their marginal productivity.

There exists an imperfect unemployment insurance mechanism, through which every low skilled worker receives a flat payment $z$ when unemployed and pays an insurance premium $q$ when employed. ${ }^{10}$ High skilled workers do not pay into any unemployment insurance scheme. This is akin to assume that the unemployment insurance scheme is actuarially fair, since high skilled workers do not pay contributions to an unemployment insurance scheme from which they never receive any benefit and, as later shown, the expected cost of insurance for low skilled workers is equal to its expected return. Alongside the unemployment insurance scheme, there exists a social benefit scheme whereby every low skilled worker, no matter if employed or unemployed, receives a lump sum transfer $b$, financed by taxing the wage income of the low skilled (contributory principle) at rate $\tau^{L}$. Notice that, although workers and unions take as given the insurance premium $q$ and the tax rate $\tau^{L}$, both $q$ and $\tau^{L}$ are endogenously determined at the aggregate general equilibrium level, so to ensure balanced budgets for the unemployment insurance and the social benefit schemes.

Starting with the assumption of fixed units of labor for high skilled workers, few comments are in order. Since skill formation takes time to acquire, it is conceivable that in a closed economy (or in a common market) the labour supply of high skilled workers is fixed in the short-medium run. ${ }^{11}$

With regard to the unemployment insurance scheme, the choice of a system characterised by receiving a constant benefit when unemployed and by paying a constant premium (tax) when employed, conveniently, keeps the analysis simple; it also, typically, occurs in private voluntary unemployment insurance schemes and, more importantly, has been identified in the literature as a good approximation of an optimal insurance system (see, e.g., Davidson and Woodbury 1997, Shimer and Werning 2007).

The assumption of two separate budget constraints, one for the unemployment insurance scheme and one for the social benefit scheme, is done for analytical convenience. It also captures the praxis of many countries in which the unemployment insurance component and the social assistance component of welfare transfers are financed from different sources.

Finally, it should be stressed that our set up can be easily generalised and, as shown in Section 4, it is robust to the case of an unemployment insurance scheme

\footnotetext{
${ }^{10}$ Dufourt et al. (2008) use similar insurance scheme and labour market structure to study local stability properties of equilibria in a dynamic set up. In their model, however, there are no high skilled workers but, instead, productive capital, and effects on employment are ignored.

${ }^{11} \mathrm{Also}$, as it will become clear shortly, considering a fixed level of employment among the high skilled workers is appealing if one wants to focus on the direct general equilibrium effects of benefits on unemployment. That is on the effects arising due to the fact that these benefits must be financed by taxes and are not due to changes in the employment of high skilled workers.
} 
financed through a payroll tax rather than a fixed premium and to the case of a single, rather than separate, budget constraints.

\section{The Low Skilled Labour Market}

In the labour market for low skilled, unions are firm specific, that is there are $M$ identical unions: one per firm. Workers are exogenously and uniformly distributed between unions and cannot move across them. Accordingly, each union represents $n_{L} \equiv N_{L} / M$ workers and aims at maximising the aggregate income of their members (unemployed and employed) $\Omega=\left[w^{L}\left(1-\tau^{L}\right)-q\right] l+z\left(n_{L}-l\right)+b n_{L}$, while firms aim at maximising profits $\Pi=A y-w^{L} l-w^{H} h$. It is assumed that, when negotiating the wage and employment of the low skilled workers, firms have already chosen the level of high skilled workers to hire. ${ }^{12}$ To obtain the efficient bargaining solution we solve the generalized Nash bargaining problem, where the firm and union returns are net of their respective fall-back (that is, net of the level of their returns in case no agreement takes place and firms do not produce). Accordingly, $w^{L}$ and $l$ are the solutions of the following problem

$$
\operatorname{Max}_{\left(w^{L}, l\right) \in \Re_{++}}\left[\operatorname{Alf}(x)-w^{L} l\right]^{\alpha}\left[\left(w^{L}\left(1-\tau^{L}\right)-q-z\right) l\right]^{1-\alpha}
$$

s.t. $l \leq n_{L}$,

where $1>1-\alpha>0$ denotes the union bargaining power. The term $A l f(x)-w^{L} l$ is the firm's profits net of its fall-back (that is, net of high skilled workers wage costs), and the term $\left(w^{L}\left(1-\tau^{L}\right)-q-z\right) l$ denotes the income of union members net of their fall-back (that is, net of unemployment and social benefits that should be paid to all members in case negotiations fail). Clearly, workers are willing to supply labour only if income when employed is higher than what they would receive if

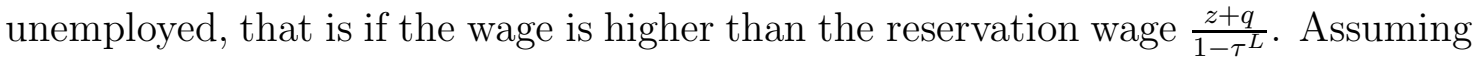
the existence of unemployment, $l<n_{L}$, the solution to this problem is given by

$$
\begin{gathered}
w^{L}=\mu(x) M P L(x) \\
M P L(x)=R W,
\end{gathered}
$$

where $\mu, M P L$ and $R W$ denote, respectively, the wage mark-up factor, the marginal productivity of low skilled labour and the real reservation wage, and are defined as follows,

$$
\begin{gathered}
\mu(x) \equiv \frac{A\left[f(x)-\alpha f^{\prime}(x) x\right]}{M P L(x)}=\frac{1-\alpha s(x)}{1-s(x)}>1 \\
M P L(x) \equiv A\left[f(x)-f^{\prime}(x) x\right] \\
R W \equiv \frac{z+q}{1-\tau^{L}} .
\end{gathered}
$$

\footnotetext{
${ }^{12}$ Think of high skilled workers as performing essential managerial tasks and hired on a retainer agreement type of contract.
} 
After straightforward computations, the elasticities of the wage mark-up and of the marginal productivity of labour with respect to skill intensity are, respectively,

$$
\varepsilon_{\mu, x}=\frac{s(x)(1-\alpha)}{1-\alpha s(x)} \frac{\sigma(x)-1}{\sigma(x)}>0 \text { and } \varepsilon_{M P L, x}=\frac{s(x)}{\sigma(x)}>0 .
$$

The wage mark-up and the marginal product of labour are therefore both increasing in skill intensity (hence decreasing in $l$ ). It is also worth emphasizing, for later purposes, that the wage bill $w^{L} l$ is increasing in employment $l$, as can be easily checked using the elasticities above. Notice that, since wages decrease when $l$ increases, in principle, the wage bill could also be decreasing in employment; however, this is ruled out when $\sigma>s$. In fact, if the elasticity of substitution between high skilled and low skilled workers is large enough, increases in employment more than compensate the fall in the wage, leading to an overall increase in the wage bill. Accordingly we can establish the following.

Lemma 1 Given $\sigma>1$, the wage mark-up $\mu$ is decreasing in $l$ and the wage bill $w^{L} l$ is increasing in $l$.

Employment of low skilled workers $\left(l_{P E}\right.$ in Figure 1 below) is determined, for a given $h$, by (4) through the equality between the marginal productivity of low skilled labour $M P L(x)$ and the reservation wage $R W$. In partial equilibrium, the reservation wage, is taken as given. This is represented by the flat schedule in Figure 1. Using (4) and (3), the equilibrium wage of the low skilled workers is given by $w^{L}=\mu(x) R W$. Not surprisingly, $w^{L}$ is set as a mark-up over the $R W$ (labelled $w_{P E}^{L}$ in Figure 1 below). Note that unemployment is involuntary at the individual level, since for $w_{P E}^{L}$ all workers would like to be employed but only $l_{P E}$ are offered employment.

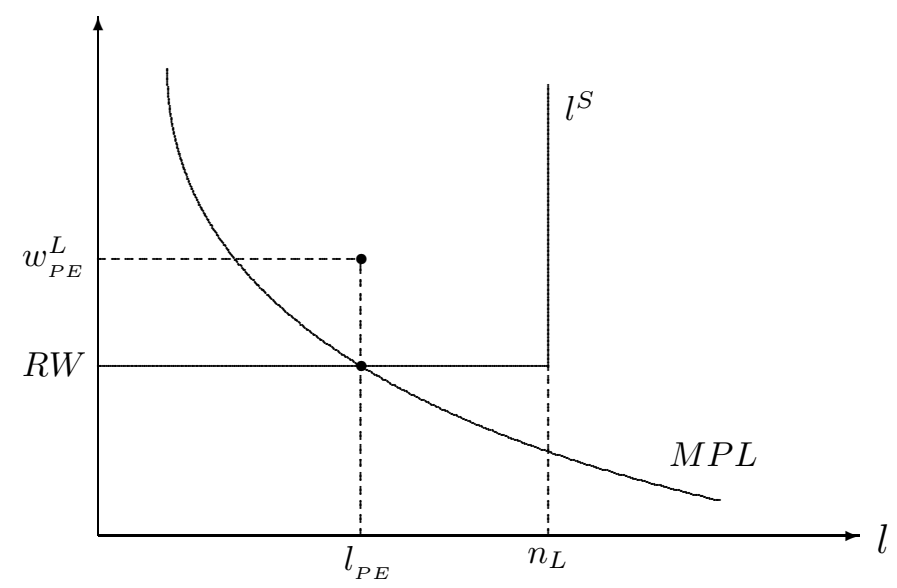

Figure 1: Low skilled labour market: partial equilibrium

At the partial equilibrium level, where the insurance premium and the tax rate to finance the social benefit are taken as given, it is immediate to see that any increase 
in the unemployment benefit $z$ pushes up the real reservation wage (see (7)) and decreases the employment level. This can be related to the negative moral hazard effect of unemployment benefits. ${ }^{13}$ However, as we shall see, in general equilibrium, the reservation wage and unemployment end up decreasing with an increase in the unemployment benefit, reversing the potential negative effects of moral hazard. Note also that, although the social benefit $b$ does not influence directly the real reservation wage, it will affect its level at general equilibrium through the tax rate $\tau^{L}$ levied to finance it.

Anticipating the bargaining outcome, the representative firm, aiming to maximize profits $\Pi$, determines the demand for high skilled labour $h$ according to,

$$
w^{H}=\alpha A f^{\prime}(x) .
$$

The expression above, together with (3), implies that profits are zero in equilibrium.

\section{General equilibrium}

In general equilibrium the insurance premium $q$ paid by low skilled workers becomes endogenous due to the balancing of the insurance scheme budget constraint,

$$
q l=z\left(n_{L}-l\right) .
$$

Note that, in a symmetric equilibrium, the ratio $\frac{n_{L}-l}{n_{L}}\left(\frac{l}{n_{L}}\right)$ denotes the unemployment (employment) rate among low skilled workers and, since workers are treated anonymously, it corresponds to the probability of becoming unemployed (employed). Accordingly, the above represents an actuarially fair insurance scheme. Note also that, had we considered that unemployment insurance was provided directly by the government and financed by a standard payroll tax, the term $q$ would represent the tax paid by an individual worker, and expression (10) would represent the unemployment insurance balanced budget constraint. ${ }^{14}$

The tax rate that finances the social benefit scheme, also, becomes endogenous in general equilibrium. The social benefit budget constraint reads as

$$
\tau^{L} w^{L} l=b n_{L}
$$

which, by use of (3), gives the tax rate,

\footnotetext{
${ }^{13}$ The moral hazard effect of unemployment benefits is usually defined as the extent to which benefit increases lead to longer unemployment spells. In our paper, where search is not modelled, the moral hazard effect can be thought as the extent to which benefits increase unemployment, the link between benefits and unemployment coming from the reservation wage. See, for instance, Shimer and Werning (2008) where they state that "Under constant benefits, the worker receives a constant benefit while she is unemployed and pays a constant tax once she is employed... We show that the worker adopts a reservation wage that is increasing in both the unemployment benefit and the employment tax, a form of moral hazard." (p. 1922).

${ }^{14}$ This amounts to replace $q$ by $\delta w^{L}$, where $\delta$ denotes the wage payroll tax. In sections 4.1 and 4.2 we show that results carry over to a model with a standard payroll tax.
} 


$$
\tau^{L}=\frac{b n_{L}}{\mu(x) M P L(x) l} .
$$

Notably, the insurance premium $q$ required to fulfill the unemployment insurance budget constraint (10), and the tax rate $\tau^{L}$ required to finance the social benefit (12), are both decreasing with $l$. In fact, the higher the level of employment, the lower the probability of becoming unemployed and the lower the premium paid for unemployment insurance. Similarly, the higher the number of employed, the larger the number of contributors and the lower the burden of financing the social benefit.

Incorporating the balanced budget rules for the social benefit (12) and for the unemployment insurance scheme (10) into the solution (4), provides the equilibrium condition for the low skilled employment level. After rearranging terms, this condition can be re-written as ${ }^{15}$

$$
\begin{aligned}
M P L(x) & =G E R W(l) \\
\text { with } G E R W(l) & \equiv z \frac{n_{L}}{l}+b \frac{n_{L}}{l \mu(x)}, x \equiv h / l
\end{aligned}
$$

where the wage mark-up factor $\mu(x)$ is given by (5). In view of (4), the expression for $G E R W$ can be interpreted as the reservation wage evaluated at the general equilibrium and, as it will become clear shortly, plays a crucial role in the model.

Notice, in particular, that the $G E R W$ is more responsive to changes in the unemployment insurance benefit than to changes in the social benefit. This property will also be relevant later on in the analysis, and can be rationalised as follows. First, recall that the reservation wage is increasing in $\tau^{L}$ (cf.(7)). Then looking at expressions (3) and (11)-(12) notice that, for a given level of employment, the higher is $\mu$ (that is the lower is $\alpha$, cf. (5)) the higher is $w^{L}$ and the lower is $\tau^{L}$. That is unions are able, through the wage mark-up, to boost wages and to reduce the implicit tax rate needed to finance the social benefit. The same does not apply to the unemployment insurance benefit premium which is independent of $w^{L}$. In short, ceteris paribus, the social benefit implicit tax rate is lighter the higher the bargaining power of unions, and the response of the reservation wage associated with an increase in the social benefit is mitigated by the presence of union power. Accordingly, union bargaining power implies a muter response of the reservation wage to an increase in the social benefit compared to an equivalent increase in the unemployment insurance benefit. ${ }^{16}$

\footnotetext{
${ }^{15}$ Using $(z+q)=n_{L} z / l$ from the unemployment insurance budget constraint (10) and $\tau^{L}$ from $(12)$ we obtain $(z+q) /\left(1-\tau^{L}\right)=\left[\left(n_{L} z / l\right) \mu(x) M P L(x) l\right] /\left[\mu(x) M P L(x) l-b n_{L}\right]$. Finally, substituting the above expression for $R W$ in (4), after straightforward computations, we obtain (13).

${ }^{16}$ Note that this mechanism does not depend on the unemployment insurance benefit being financed by a flat premium (tax) per employed worker. In fact, when we consider the case of an unemployment insurance benefit financed via a payroll tax (see Section 4.1), we still find that the $G E R W$ is more responsive to changes in $z$ than to changes in $b$. The reason is that the social
} 
Turning to the high skilled employment level $h$, since labour supply is fixed at $N_{H}$ and there are $M$ firms, at equilibrium we have,

$$
h=n_{H} \equiv N_{H} / M \text { and } x=n_{H} / l .
$$

Using (13) and (14) we obtain the equilibrium level of employment of low skilled $l$ (in Figure 2, labelled $l_{G E}$ ). Existence and uniqueness are proven in Appendix I, while in Appendix II we show that the GERW schedule is negatively sloped and steeper than the $M P L$ schedule. Graphically, the low skilled labour market in general equilibrium is illustrated in Figure 2 below.

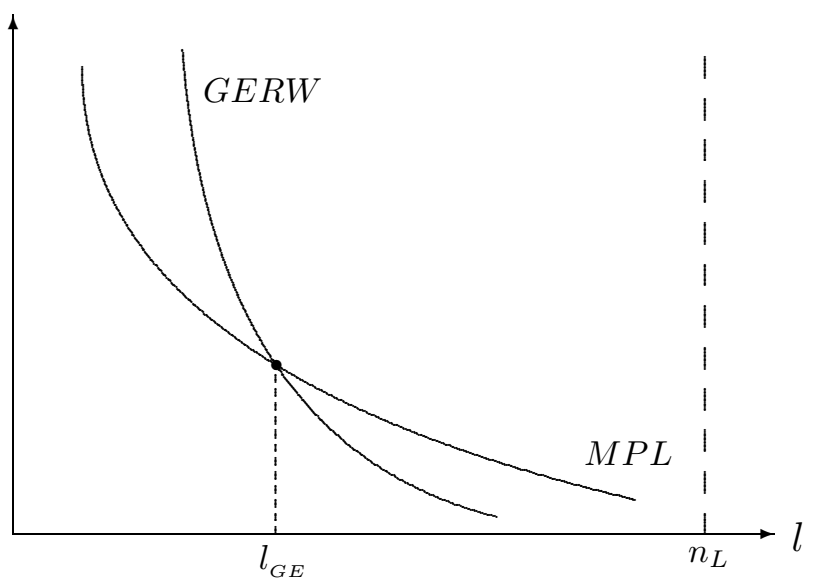

Figure 2: Low skilled labour market: general equilibrium

Compared to Figure 1, the $R W \equiv \frac{z+q}{1-\tau^{L}}$ schedule is no longer flat. In fact, as $l$ increases the insurance premium, $q=z\left(n_{L}-l\right) / l$, required to fulfill the unemployment insurance budget constraint (10) and the tax paid by each low skilled employed worker to finance the social benefit, $\tau^{L} w^{L}=b n_{L} / l$ (see (11)), both decrease. The implicit tax rate to finance the unemployment insurance $q / w^{L}=z\left(n_{L}-l\right) / w^{L} l$, and the tax rate $\tau^{L}=b n_{L} / w^{L} l$ levied to finance the social benefit also decreases with $l$ since, by Lemma 1 , the wage bill increases with $l$. All of the above implies that, in general equilibrium, the reservation wage is decreasing in $l$ and, likewise, the tax burden (whether measured in terms of tax rates or in terms of taxes paid per worker). The following Lemma summarises.

Lemma 2 In general equilibrium, the unemployment insurance premium (tax), the social benefit tax rate, the reservation wage and the tax burden are all decreasing in the level of employment.

benefit is paid to both unemployed and employed $\left(n_{L}\right)$ and, thereby, the decrease in the implicit tax associated with higher union power is larger for the social benefit, $\tau^{L}=\frac{1}{\mu(x)} \frac{b}{M P L l} n_{L}$, than for the unemployment benefit paid only to the unemployed, $\delta=\frac{1}{\mu(x)} \frac{z}{M P L l}\left(n_{L}-l\right)$. Cf. (23) in Section 4.1. 


\section{Unemployment Insurance vs Social Benefit}

This section begins by studying the effects on employment of less generous unemployment insurance benefits coupled with more generous social benefits, to be followed by the analysis of the effects on income levels and associated welfare implications.

\section{Effects on employment}

In general equilibrium, the employment effects of changing the unemployment benefit $z$ and/or the social benefit $b$ are computed as follows. ${ }^{17}$

From (13), by use of (1)-(3), (5), (11) and (12), we obtain ${ }^{18}$ the effect of a change in $b$ for a given $z$,

$$
\frac{d l}{d b}=\frac{n_{L}}{w^{L}} \frac{\sigma(1-\alpha s)}{D} .
$$

and the effect of a change in $z$ for a given $b$,

$$
\frac{d l}{d z}=\mu \frac{n_{L}}{w^{L}} \frac{\sigma(1-\alpha s)}{D} .
$$

The term $D \equiv \sigma\left[(1-\alpha s)-(1-\alpha) s \tau^{L}\right]-s\left[(1-\alpha s)-(1-\alpha) \tau^{L}\right]$ in the denominator of (15) and (16) is positive since: $\sigma>s,(1-\alpha s) /(1-\alpha)>1>\tau^{L}$ and $0<(1-\alpha s)-(1-\alpha) \tau^{L}<(1-\alpha s)-(1-\alpha) s \tau^{L}$. Accordingly, $\frac{d l}{d b}$ and $\frac{d l}{d z}$ are both positive. $^{19}$

The key to understanding the above results lies in the fact that, in general equilibrium, the wage and taxes are endogenous (cf. Lemma 2) and interdependent. In effect, when taxes are endogenous, the level of employment determines the level of tax via the balanced-budget requirement, but the tax in turn affects the level of employment via the labour market. In other words, as higher levels of employment reduce the tax burden and the reservation wage, unions/workers become more inclined to work more at lower wages (gross of taxes) and firms respond with a higher labour demand, leading to increased employment and lower tax burden for the low skilled. In short, the general equilibrium adjustments to higher $b$ or $z$ generate (demand and supply) incentives consistent with higher employment. Notice that

\footnotetext{
${ }^{17}$ Hereafter, to simplify the presentation, we will use $\sigma, s, \mu$, and so on, to refer to variables evaluated at the initial equilibrium value of $x$ (that is $\sigma(x), s(x), \mu(x)$ and so on).

${ }^{18}$ Detailed derivations of expressions (15) and (16) are provided in Appendix III.

${ }^{19}$ Grandmont (2008) in an overlapping generations (OLG) set up, with efficiency wages and unemployment benefits indexed to wages financed by a payroll tax, and Dos Santos Ferreira et al. (2015) in OLG economies with wage bargaining and flat unemployment benefits financed by a payroll tax, also find a positive effect of unemployment benefits on employment. However, both papers focus on the stability properties of equilibria and ignore social benefits. Grandmont shows that unemployment subsidies facilitate the occurrence of indeterminacy, and Dos Santos Ferreira et al. show that social norms in the labour market matter for the emergence of endogenous fluctuations.
} 
the mechanism at work in our model corresponds to a fiscal externality associated to the financing of the benefits. ${ }^{20}$

Comparing (16) with (15) it is immediate to see that the effect on employment of a change in $z$ is larger than that of an equal change in $b$, since the wage mark-up factor is higher than one; suggesting that higher social benefits, coupled with lower unemployment insurance benefits, are detrimental for employment.

Proposition 1 A shift from unemployment insurance benefits to social benefits reduces the level of employment.

This outcome hinges on the fact, explained earlier, that the equilibrium reservation wage is more sensitive to changes in the unemployment insurance benefit $z$ than to changes in the social benefit $b$.

Graphically, the effect on low skilled employment of increasing $z$ (from $z_{0}$ to $z_{1}$ ) or $b$ (from $b_{0}$ to $b_{1}$ ) is illustrated in Figure 3 below.

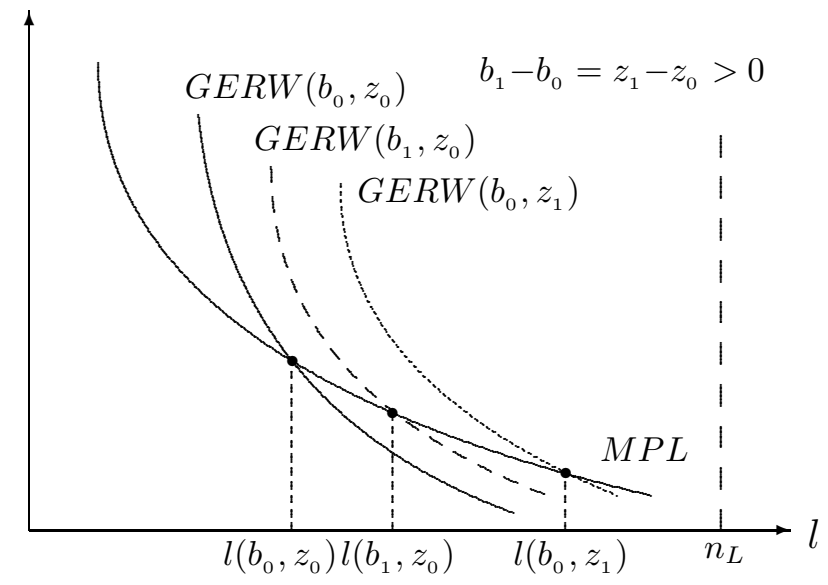

Figure 3: Low skilled labour market: effects of equal increases in the social benefit $b$ and in the unemployment benefit $z$

In words, an increase in $z$ or $b$ triggers an upward shift of the $G E R W$ schedule; since the latter is decreasing in $l$, and steeper than the $M P L$, the level of employment increases. ${ }^{21}$ However, as the shift of the $G E R W$ is larger under an increase in

\footnotetext{
${ }^{20}$ The unemployment insurance premium and the benefit tax are taken as given at the private decision level over employment, but influence labour market conditions and the (general) equilibrium level of employment via the balanced-budget requirements. Interestingly, this equilibrium adjustment is also isomorphic to the working of a leisure externality, as shown by Lloyd-Braga et al. (2014) in proposition 3, p. 225. This type of externality is such that the utility level of leisure decreases with higher levels of employment in the economy, so that the wage required by workers to accept a job (reservation wage) decreases with the employment level in the economy.

${ }^{21}$ Interpreting the $M P L$ schedule as a labor demand curve and the $G E R W$ as a labor supply curve, we can see that the upwards shift in the $G E R W$, caused by the increase in the unemployment benefit or in the social benefit, generates excess supply that calls for a lower (reservation) wage and a higher level of employment, as per classic law of demand and supply.
} 
$z$ than under an increase in $b$, the effect on employment too is larger in the case of a higher $z$ than in the case of a higher $b$, that is $l\left(b_{0}, z_{1}\right)-l\left(b_{0}, z_{0}\right)>l\left(b_{1}, z_{0}\right)-l\left(b_{0}, z_{0}\right)$.

Notably, given Lemma 2 and employment increasing more with $z$ than with $b$ (Proposition 1), it follows that the tax burden associated with an increase in the unemployment insurance, $z\left(n_{L}-l\right) / w^{L} l$, is lower than the tax burden associated with an equivalent increase in the social benefit, $b n_{L} / w^{L} l$.

Proposition 2 A shift from unemployment insurance benefits to social benefits is associated with a higher tax burden.

\section{Effects on income}

Let us first clarify notation. Variables in small letters stand for the income of representative workers: $y^{l} \equiv\left(1-\tau^{L}\right) w^{L}+b-q$ represents the income of an employed low skilled worker, $y^{u}$ denotes the income of an unemployed low skilled worker and $y^{H} \equiv w^{H}$ stands for the income of a high skilled worker. Variables in capital letters represent aggregate incomes: $Y^{L} \equiv y^{l} l+y^{u}\left(n_{L}-l\right)$ denotes aggregate income of low skilled workers and $Y^{H} \equiv w^{H} n_{H}$ stands for the aggregate high skilled income. Crucially, since the level of employment $l$ is affected by the policies, changes in aggregate low skilled income $Y^{L}$ are not merely determined by changes in the corresponding representative incomes $y^{l}$ and $y^{u}$. Also, note that $Y^{L} / n_{L}$ represents the expected (ex-ante) income of the low skilled, ${ }^{22}$ while $y^{l}$ and $y^{u}$ refer to earnings of low skilled workers whose employment status does not change. This distinction matters when it comes to evaluate the desirability of the policy, which we carry out later on.

Using (3), (9), (10), (11) and (14), we obtain the expressions for the income of a representative worker for each type, that is

$$
\begin{gathered}
y^{l}=\mu(x) M P L(x)-z\left(\frac{n_{L}}{l}-1\right)-b\left(\frac{n_{L}}{l}-1\right) \\
y^{u}=z+b \\
y^{H}=\alpha A f^{\prime}(x) .
\end{gathered}
$$

Using (17) and (18), we obtain the expression for the aggregate income of all low skilled workers which, in the end, corresponds to the wage bill $w^{L} l$,

$$
Y^{L}=\mu(x) M P L(x) l .
$$

Let us now look at the effect of policy changes. By direct inspection of (18), income of the representative unemployed low skilled worker is the same under a change in

\footnotetext{
${ }^{22}$ Equally, it represents the earning of each low skilled if unions redistributed income among the members.
} 
$z$ or a change in $b$ of equal measure; that is $\frac{d y^{u}}{d z}=\frac{d y^{u}}{d b}=1$. Accordingly, lower unemployment insurance benefits coupled with higher social benefits have zero net effect on income of the unemployed. A high skilled worker, on the other hand, always looses with a shift from unemployment insurance to social benefits. In fact, this shift leads to a lower high skilled wage $w^{H}=\alpha A f^{\prime}(x)$, due to the decrease in the marginal productivity of high skilled workers associated with higher skill intensity $x$, ensuing the decrease in employment of low skilled workers (see Proposition 1). For the representative employed low skilled worker, after tedious computations relegated in Appendix III, we obtain that the effect of $b$ and $z$ depends, respectively, on the sign of the following expressions

$$
\frac{d y^{l}}{d b}=\frac{1}{1-\gamma}\left[\frac{B}{D}-\gamma\right]
$$

and

$$
\frac{d y^{l}}{d z}=\frac{1}{1-\gamma}\left[\mu \frac{B}{D}-\gamma\right]
$$

where: $B \equiv \sigma\left[(1-s)-s(1-\alpha)\left(1-\tau^{L}\right)\right]-s \alpha(1-s)$, the variable $\gamma \equiv \frac{n_{L}-l}{n_{L}}$ denotes the unemployment rate and the term $D>0$ was defined earlier (see (15)(16))

When $\mathrm{B}$ is positive we have $\frac{d y^{l}}{d z}>\frac{d y^{l}}{d b}$ for $\mu>1(0<\alpha<1)$. Since $B=$ $(\sigma-s)(1-s)>0$ in the limit case of $\alpha=1$, by continuity, $B$ is still positive for $\alpha<1$ as long as it is high enough (i.e., for $\mu>1$ but not too high). Furthermore, in this case, the term $\left[\frac{B}{D}-\gamma\right]$ is positive for $\gamma$ low enough. Accordingly, low union bargaining power (high $\alpha$, low $\mu$ ) and low unemployment rates $(\gamma)$ increase the likelihood of $y^{l}$ being increasing in $b$ and $z$. In this case $\frac{d y^{l}}{d z}>\frac{d y^{l}}{d b}>0$, suggesting that higher social benefits coupled with lower unemployment insurance benefits are detrimental for income of the representative employed low skilled worker.

Total income of low skilled workers (employed and unemployed) is given by (20). Differentiating (20) with respect to $b$ and $z$, and using (8), (15) and (16), gives

$$
\frac{d Y^{L}}{d b}=\frac{(\sigma-\alpha s)(1-s)}{D} n_{L}
$$

and

$$
\frac{d Y^{L}}{d z}=\mu \frac{(\sigma-\alpha s)(1-s)}{D} n_{L}
$$

Since $\sigma>1$ and $D>0$, an increase in $b$ or in $z$ unambiguously increases total income of low skilled workers. Moreover, $\frac{d Y^{L}}{d z}>\frac{d Y^{L}}{d b}$ for $\mu>1$, implying that income of all low skilled workers increases more with an increase in $z$ than with an identical increase in $b$. Since the aggregate income of high skilled workers is directly proportional to $y^{H}$, it also increases more with an increase in $z$ than with an equal increase in $b$. The following Proposition summarises. 
Proposition 3 A shift from unemployment insurance benefits to social benefits leads to:

(i) lower income for the representative high skilled worker and for high skilled workers as a whole;

(ii) lower income for the representative employed low skilled worker, if union bargaining power and unemployment rate are not high;

(iii) lower income for low skilled workers as a whole.

\section{Effects on welfare}

As stated in Proposition 3, a shift from unemployment insurance to social benefits decreases incomes of the representative employed workers (low skilled and high skilled) and has no effect on the income of unemployed low skilled workers. ${ }^{23}$ Since employment is relatively lower with the social benefit, no single worker gains from such a shift, if all unemployed workers receiving a lower $z$ were also unemployed under a higher $b$. Accordingly, if there was no change in the employment status of low skilled workers, replacing the social benefit by an unemployment benefit of equal size would be a Pareto improvement: high skilled and employed low skilled would be better off and the low skilled unemployed under both policies would be indifferent.

If we consider welfare in ex-ante terms, that is before the employment status for low skilled workers is revealed, and assume individual utility linear in income (risk neutral agents), a shift from the social benefit to the unemployment subsidy would increase social welfare from an utilitarian perspective. In fact, the aggregate incomes of high skilled workers $Y^{H}$ and of low skilled workers $Y^{L}$ will increase with the shift. Note that $Y^{L} / n_{L}=(1-\gamma) y^{l}+\gamma y^{u}$ is the expected income of low skilled workers, as the unemployment rate $\gamma$ denotes the probability that a low skilled worker will be unemployed. This means that a low skilled worker may expect to be better off with this shift, since ex-ante her expected utility, or income, increases not only because her income if employed is higher, but also because there is a higher probability that she will find a job. ${ }^{24}$

Contemplating other social welfare functions, more general than the utilitarian, we still obtain higher welfare under a shift from social benefits to unemployment benefits. This involves comparing an initial income distribution with that materialising after a decrease in the social benefit $b$ coupled with an identical increase in the

\footnotetext{
${ }^{23}$ In this welfare analysis we assume that the conditions on $\alpha$ and $\gamma$ stated on Proposition 3 hold.

${ }^{24}$ Recall that an employed low skilled worker has a higher income than an unemployed, that is $y^{l} \equiv\left(1-\tau^{L}\right) w^{L}+b-q>y^{u} \equiv z+b$; since, with union power, wage $w^{L}=\mu M P L$ is higher than the reservation wage $R W \equiv \frac{z+q}{1-\tau^{L}}$. See (3)-(4). This also means that unemployment is involuntary at the individual level.
} 
unemployment benefit $z$. Saposnik (1981) has shown that, the partial ordering of income distributions defined by the rank-dominance relation is identical with that defined by a social welfare function, which is additively separable in monotone individual utility functions (i.e., individual utility increasing in the respective individual income) or, more generally, with that defined by a social welfare function that is monotone in individual incomes and satisfies the symmetry (anonymity) property. According to the first order dominance criterion by Saposnik (1981): a distribution first-order-dominates another if and only if the income of the individual in each rank of the former distribution is at least as great as the income of the individual with the corresponding rank of the latter distribution or, as stated by Fields (2005), if (weakly) fewer individuals are below any income level under the former distribution. In the present paper, it is immediate to check that if there is a shift from the social benefit to the unemployment benefit, the new income distribution will rank-dominate the income distribution prior to the change. As an example, consider the standard case $y^{u}=b+z<y^{l}<y^{H}$ illustrated in Figure 4 below.

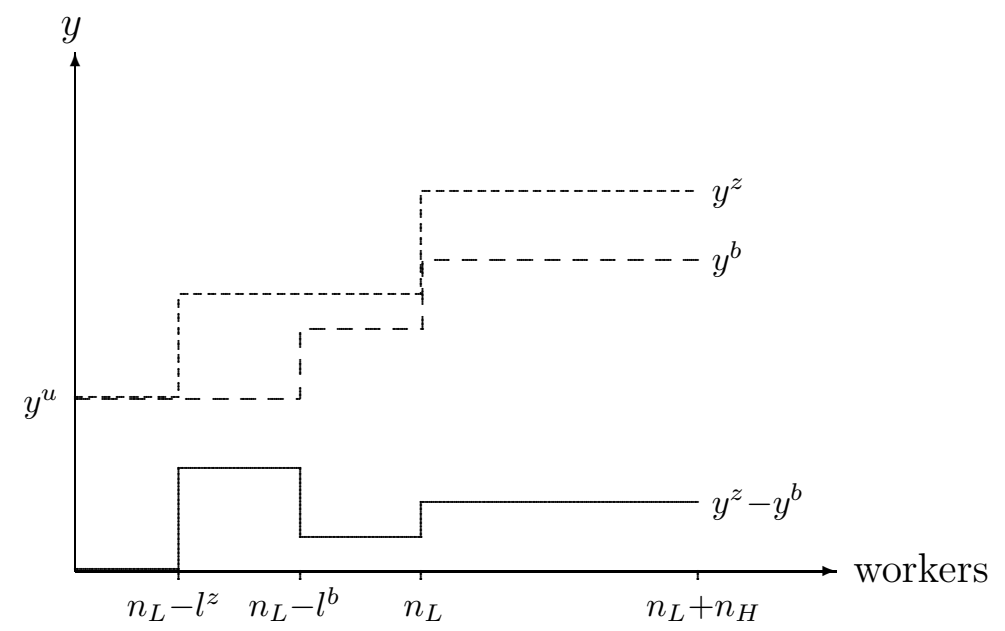

Figure 4: Income distributions with $b$ and $z$

Let $l^{b}$ and $l^{z}$ denote, respectively, the number of employed low skilled workers under an increase in the social benefit $b$ and the number of employed low skilled workers under an identical increase in the unemployment insurance $z$. Since $\frac{d y^{u}}{d b}=$ $\frac{d y^{u}}{d z}=1$, the income of the poorest individuals $n_{L}-l^{z}$ does not change with a shift from $b$ to $z$, and remains at the same initial level $y^{u}=b+z$. On the other hand, employment and income of the representative employed workers, low skilled and high skilled, increase with the policy shift. Graphically, the income distribution schedule under an increase in the unemployment insurance (represented by $y^{z}$ ) lies above the corresponding income distribution under an increase in the social benefit (represented by $y^{b}$ ). This implies that, under an increase in $z$ (weakly) fewer workers are below any generic income level $y$; which is illustrated by the fact that the difference in the income schedules $y^{z}-y^{b}$ is never negative. 


\section{Extensions}

In this section we discuss how the model is robust to various extensions, and what would happen had we considered a system in which the social benefit was paid not according to a contributory principle. We start by considering the case where a payroll tax finances the unemployment benefit and show that the main proposition in the paper extends to this case as well. Equally we show that assuming separate or unique budget constraints makes no difference, and that the results for the efficient bargaining carry over to models with bargain over the wage. Finally, we look at the case in which the social benefit is financed by taxing the high skilled workers instead of the low skilled. In all these alternative scenarios a shift from unemployment insurance benefits to social benefits has a detrimental effect on employment.

\subsection{Payroll tax}

Assume that $q=\delta w^{L}$; that is the unemployment insurance scheme is financed through a wage payroll tax $\delta$. Keeping, for now, separate budget constraints for the social benefit and for the unemployment insurance schemes, these are given by (12) and by $\delta w^{L} l=z\left(n_{L}-l\right)$, respectively. The unions' return net of their respective fallback is now $\left[\left(1-\tau^{L}-\delta\right) w^{L}-z\right] l$ and the (partial equilibrium) reservation wage is $R W=z /\left(1-\tau^{L}-\delta\right)$. Real wages of low skilled workers and employment of high skilled workers are still given, respectively, by (3) and (14). It can be easily checked that, in general equilibrium, employment of low skilled $l$ is determined from, ${ }^{25}$

$$
\begin{aligned}
M P L(x) & =G E R W^{*}(l) \\
\text { with } G E R W^{*}(l) & \equiv(z+b) \frac{n_{L}}{l}-\frac{z(\mu(x)-1)}{\mu(x)} \frac{n_{L}-l}{l}-\frac{b(\mu(x)-1)}{\mu(x)} \frac{n_{L}}{l}
\end{aligned}
$$

Note in particular that, since $\mu>1$ the difference in the effect of $b$ and $z$ on the reservation wage comes from the fact that the unemployment benefit $z$ is paid only to those unemployed, while the social benefit $b$ is given to all low skilled. Differentiating the above, we obtain

$$
\begin{aligned}
\frac{d l}{d z} & =\frac{\sigma(1-\alpha s)[\gamma+\mu(1-\gamma)]}{D^{*}} \frac{l \gamma}{w^{L}(1-\gamma)} \\
\frac{d l}{d b} & =\frac{\sigma(1-\alpha s)}{D^{*}} \frac{l \gamma}{w^{L}(1-\gamma)}
\end{aligned}
$$

\footnotetext{
${ }^{25}$ Because the wage of low skilled workers is still given by $w^{L}=\mu(x) M P L(x)$, then, using $\delta=z\left(n_{L}-l\right) / \mu(x) M P L(x) l$ from the unemployment insurance budget constraint (10) and $\tau^{L}$ from $(12)$, we obtain $R W=z /\left(1-\tau^{L}-\delta\right)=z \mu(x) M P L(x) l /\left[\mu(x) M P L(x) l-z\left(n_{L}-l\right)-b n_{L}\right]$. The expression $G E R W^{*}$ follows from substituting $R W$ into (4).
} 
where $D^{*} \equiv \sigma\left[\left(\tau^{L} \gamma+\delta\right)(1-\alpha s)-\left(\tau^{L}+\delta\right) \gamma s(1-\alpha)\right]-s \gamma\left[(1-\alpha s)-\left(\tau^{L}+\delta\right)(1-\alpha)\right]$. The sign of the above derivatives depends on the sign of the term $D^{*}$, in which the factor multiplying $\sigma$ is positive if $\tau^{L} \gamma(1-s)+\delta[1-s(\alpha+\gamma(1-\alpha))]>0$, a condition that is satisfied since $\alpha+\gamma(1-\alpha)<1$. Therefore, given $\sigma>1$, we should expect an increase in employment when $z$ or $b$ increase under the sufficient condition $\frac{s \gamma\left[(1-\alpha s)-\left(\tau^{L}+\delta\right)(1-\alpha)\right]}{\left(\tau^{L} \gamma+\delta\right)(1-\alpha s)-\left(\tau^{L}+\delta\right) \gamma s(1-\alpha)}<1$. The latter is verified for $\tau^{L}>s$, or $\tau^{L}<s$ and a low enough unemployment rate $\gamma<\delta /\left(s-\tau^{L}\right)$, which are parameters' restrictions that can be easily fulfilled. Furthermore, note that $\gamma+\mu(1-\gamma)>1$ if $\mu>1$. Hence, when unions have some bargaining power, the change in employment following a change in $z$ is larger than the change in employment following a change in $b$, as for the case of a flat unemployment insurance premium illustrated in Section 3. Accordingly, the main proposition in the paper extends to this case.

\subsection{Payroll tax and unique budget constraint}

By relaxing the assumption of two separate constraints for the unemployment insurance scheme and for the social benefit scheme, we can write the unique budget constraint as $\tau^{L} w^{L} l=b n_{L}+z\left(n_{L}-l\right)$. Hence, the tax rate on the income of employed low skilled is now used to finance both benefits and is given by,

$$
\tau^{L}=\frac{b n_{L}+z\left(n_{L}-l\right)}{w^{L} l} .
$$

The unions' objective, net of the fall-back, becomes $\Omega=\left[\left(1-\tau^{L}\right) w^{L}-z\right] l$ and the reservation wage, at the partial equilibrium level, is given by $R W=z /\left(1-\tau^{L}\right)$. It follows that employment is determined through $M P L(x)=z /\left(1-\tau^{L}\right)$ and the wage is still given by $w^{L}=\mu(x) M P L(x)$. Taking into account the benefits' budget constraint, in general equilibrium, employment of low skilled $l$ is determined through (23). Since the equilibrium condition is identical to the one found in Section 4.1, for the case with two separate constraints and unemployment insurance financed through a payroll tax, the same conclusion applies here.

\subsection{Wage bargaining}

Here we show that identical results would have been obtained had we considered that unions and firms only negotiate over wages, the level of employment having been previously fixed by firms. This is a special scenario of the right to manage model with a reverse timing, where firms choose employment before bargaining takes place. ${ }^{26}$

Starting with the bargaining solution over wages we have:

\footnotetext{
${ }^{26}$ See Lingens (2007) who rationalises this approach for countries where, due to substantial firing costs, employment cannot be adjusted quickly.
} 


$$
\operatorname{Max}_{w^{L} \in \Re_{+}}\left[\operatorname{Alf}(x)-w^{L} l\right]^{\alpha}\left[\left(w^{L}\left(1-\tau^{L}\right)-q-z\right) l\right]^{1-\alpha},
$$

leading to

$$
w^{L}=\frac{\alpha(q+z)}{1-\tau^{L}}+(1-\alpha) A f(x)
$$

Now we consider the decision on the employment of low skilled workers, where firms maximize profits, $\operatorname{Al} f(x)-w^{L} l$, taking into account that $w^{L}$ is given by (24). This leads to

$$
A\left[f(x)-f^{\prime}(x) x\right]-w^{L}+(1-\alpha) A f^{\prime}(x) x=0
$$

Substituting (24) in (25) we obtain $M P L(x)=(q+z) /\left(1-\tau^{L}\right)$ and, using this relationship in (24), we obtain $w^{L}=A\left[f(x)-\alpha f^{\prime}(x) x\right]$. These two expressions are identical to those we have obtained from the efficient bargain solution.

\subsection{Social benefit funded by high skilled (redistributory principle)}

We consider now a scenario in which all low skilled workers receive the social benefit but do not contribute to its funding. Setting $\tau^{L}=0$ in the Nash bargaining problem of Section 2, it is immediate to check that the partial equilibrium low skilled employment condition (4) still applies, with $R W \equiv z+q$. Also, the wage of low skilled workers is still given by (3). Since the social benefit is now funded by high skilled workers, the budget constraint for the social benefit scheme, in this case, reads as follows

$$
\tau^{H} w^{H} h=b n_{L},
$$

where $\tau^{H}$ is a proportional tax levied on the high skilled wage income. This tax rate, using (14) and (9) in (26), can be written as

$$
\tau^{H}=\frac{b n_{L}}{A \alpha f^{\prime}(x) n_{H}}
$$

with $x=n_{H} / l>n_{H} / n_{L}$.

The general equilibrium reservation wage is directly obtained from (4) using $q+z=z n_{L} / l$ and employment $l$ is determined by,

$$
M P L(x)=G E R W^{* *}(l) \equiv \frac{z n_{L}}{l} .
$$

Since $b$ (or $\tau^{H}$ ) has no influence on $G E R W^{* *}$, or on the equilibrium conditions, the level of employment/unemployment and skill intensity $x$ are unaffected by a change in the social benefit, which in turn implies, by (10), that the unemployment 
insurance premium is unchanged. Real wages of high skilled and of low skilled, given by (9) and (3), do not change either. However, the tax rate on skilled income has to increase proportionally with $b$ (see (27)) so that the per capita income of high skilled workers decrease, $\frac{d y^{H}}{d z}<0$, and per capita income of all low skilled

workers increases one-for-one with $b, \frac{d y^{l}}{d b}=\frac{d y^{u}}{d b}=1$. In other words, under a redistributory principle, a social benefit to all low skilled workers does not influence the employment level and has a purely redistributive effect, increasing the income of all low skilled workers at the expense of the high skilled.

In order to compute the changes in employment due to an increase in the unemployment benefit, we use expression (16) with $\tau^{L}=0$ to obtain $\frac{d l}{d z}=\mu \frac{n_{L}}{w^{L}} \frac{\sigma}{\sigma-s}>0$. Hence, in this case too, a policy of higher social benefits coupled with lower unemployment insurance benefits implies a decrease in employment.

\section{Conclusion}

In many countries governments are reconsidering the role of welfare provision and attempting to reform the welfare system. The main impetus for such reforms comes from the concern that some welfare benefits may have undesirable effects on incentives; particularly, through their impact on labour supply. In some countries, notably the United Kingdom, successive reforms have favoured a larger role for income assistance and a lesser role for unemployment insurance. More generally, the proponents of replacing unemployment insurance with a guaranteed minimum income make an even stronger case, arguing that since a minimum guaranteed income would not phase out there would be no reduced incentive to seek work. In the present paper we have argued that such a move can be counterproductive. Our results show that reducing unemployment insurance benefits in favour of social benefits reduces employment in general equilibrium and also income of low skilled workers, for relatively small distortions in the labour market. Although our contribution is theoretical, the experience of Nordic countries suggests that there is no strong link between unemployment insurance generosity and unemployment. If anything, these countries, that have a generous voluntary unemployment insurance system together with a stronger role for collective bargaining, fare better in terms of employment and income levels of low skilled workers. In terms of policy implications, our analysis suggests that to support higher employment, systems grounded in actuarially fair unemployment insurance schemes are to be preferred and strengthened.

Clearly, other policies can be devised to enhance the superiority of unemployment benefits: for instance, adding a re-employment bonus to the unemployment insurance benefit. Under such schemes, workers receive unemployment insurance benefits while unemployed, but get a cash bonus if they find a job sufficiently quickly. These programmes were tested in the US in the 1980s in Illinois, Washington, Pennsylvania and New Jersey with promising results, as documented by Davidson and Woodbury (1993). In their theoretical model, supported by calibration exercises, 
Davidson and Woodbury show that, when re-employment bonuses are added to unemployment insurance, unemployment tends to fall, suggesting that such bonuses promote better job matching. Along similar lines, a recent paper by Mazur (2016) also finds, using a calibrated model, that there is a positive welfare effect when unemployment benefits are also available to job quitters, because it allows workers on low wages to search for a better job match. Our conjecture is that adding a re-employment bonus would make unemployment insurance even more attractive in our set up. We leave this issue for future research.

\section{References}

Acemoglou, D., 2002. Technical Change, Inequality, and the Labor Market. Journal of Economic Literature, 40, 7-72.

Acemoglou, D., 2003. Patterns of Skill Premia. The Review of Economic Studies, 70, 199-230.

Atkinson, A., 1995, Public Economics in Action: The Basic Income/FlatTax Proposal. Oxford: Oxford University Press.

Autor, D. H., Katz, L. F. and Kearney, M. S., 2008. Trends in U.S. wage inequality: revising the revisionists. The Review of Economics and Statistics, 90, 300-323.

Beveridge, W., 1942. Social Insurance and Allied Services. Report Presented to Parliament by Command of His Majesty.

Blundell, R., 2001. Welfare Reform for Low Income Workers. Hicks Lecture 1999, Oxford Economic Papers, 53,18-214.

Cahuc, P. and Lehmann, E., 2000. Should unemployment benefits decrease with the unemployment spell? Journal of Public Economics, 77, 135-153.

Card, D., 2009. Immigration and Inequality. American Economic Review, 99, 1-21.

Chetty, R., 2008. Moral hazard versus liquidity and optimal unemployment insurance. Journal of Political Economy, 116, 173-234.

Davidson, C. and Woodbury, S., 1993. The Displacement Effect of Reemployment Bonus Programs. Journal of Labour Economics, 11, 575-605.

Davidson, C. and Woodbury, S., 1997. Optimal unemployment insurance. Journal of Public Economics, 64, 359-387.

Dos Santos Ferreira, R., Lloyd-Braga, T. and Modesto, L., 2015. The destabilizing effects of the social norm to work under a social security system. Mathematical Social Sciences, 76, 64-72.

Dufourt, F., Lloyd-Braga, T. and Modesto, L. 2008. Indeterminacy, Bifurcations and unemployment. Macroeconomic Dynamics, 12 (Supplement 1) 75-89. 
Fields, G., 2005. A welfare economic analysis of labor market policies in the HarrisTodaro model. Journal of Development Economics, 76, 127-146.

Grandmont, J.-M., 2008. Negishi-Solow efficiency wages, unemployment insurance and dynamic deterministic indeterminacy. International Journal of Econonmic Theory 4, 247-272.

Howell, D. R. and Rehm, M., 2009. Unemployment compensation and high European unemployment: a reassessment with new benefit indicators. Oxford Review of Economic Policy, 25, 60-93.

Katz, L. F. and Murphy, K. M., 1992. Changes in Relative Wages, 1963-1987: Supply and Demand Factors. The Quarterly Journal of Economics, 107, 35-78.

Lalive, R., Landais, C. and Zweimuller, J., 2015. Market Externalities of Unemployment Insurance Extension Programs. American Economic Review, 105, 3564-3596.

Lingens, J., 2007. Time is everything: the labour market effects of union wage bargaining. Economics Bulletin, 10, 1-11.

Lloyd-Braga, T., Modesto, L. and Seegmuller, T., 2014. Market distortions and local indeterminacy: A general approach. Journal of Economic Theory, 151, 216247.

Mazur, K., 2016. Can welfare abuse be welfare improving?. Journal of Public Economics, 141, 11-28.

OECD, 2013. Redistribution Policy In Europe and the United States. OECD Social, Employment and Migration Working Papers No. 150.

Parsons, D., Tranaes, T., and Lilleor, E., 2015. Voluntary Public Unemployment Insurance. IZA Discussion Paper Series, n. 8783.

Saposnik, R., 1981. Rank dominance in income distributions. Public Choice, 86, $147-151$

Shavell, S. and Weiss, L, 1979. The Optimal Payment of Unemployment Insurance Benefits over Time. Journal of Political Economy, 87, 1347-1362.

Shimer, R. and Werning, I., 2007. Reservation Wages and Unemployment Insurance. The Quarterly Journal of Economics, 122, 1145-1185.

Shimer, R. and Werning, I., 2008. Liquidity and Insurance for the Unemployed. American Economic Review, 98, 1922-1942.

Tatsiramos, K., 2009. Unemployment insurance in Europe: unemployment duration and subsequent employment stability. Journal of the European Economic Association, 7, 1225-1260 


\section{Appendix I}

\section{Existence and uniqueness of equilibrium with unemployment}

We consider a technology with a constant elasticity of substitution $\sigma>1$ :

$$
f(x)=\left(a x^{\frac{\sigma-1}{\sigma}}+1-a\right)^{\frac{\sigma}{\sigma-1}}
$$

with

$$
\begin{aligned}
f^{\prime}(x) & =a x^{-1 / \sigma}\left(a x^{\frac{\sigma-1}{\sigma}}+1-a\right)^{\frac{1}{\sigma-1}} \\
f(x)-f^{\prime}(x) x & =(1-a)\left(a x^{\frac{\sigma-1}{\sigma}}+1-a\right)^{\frac{1}{\sigma-1}}
\end{aligned}
$$

Recall that, at equilibrium, full employment of high skilled workers implies $n_{H}=h$ and that the equilibrium level of $l$ is given by (13), i.e., it has to satisfy: $A\left[f(x)-f^{\prime}(x) x\right] l=z n_{L}+\frac{b n_{L}}{\mu}$, with $\mu \equiv\left[f(x)-\alpha f^{\prime}(x) x\right] /\left[f(x)-f^{\prime}(x) x\right]$ and $x=n_{H} / l$.

Using (28) we can write $\mu=\frac{a x^{\frac{\sigma-1}{\sigma}}(1-\alpha)+1-a}{1-a}$ and according to (13), we have:

$$
n_{L} z=G(l)
$$

with

$$
\begin{aligned}
G(l) & \equiv(1-a) A\left(a n_{H}^{\frac{\sigma-1}{\sigma}} l^{\frac{(\sigma-1)^{2}}{\sigma}}+(1-a) l^{\sigma-1}\right)^{\frac{1}{\sigma-1}} \\
& -\frac{(1-a) b n_{L}}{\left(a n_{H}^{\frac{\sigma-1}{\sigma}} l^{\frac{1-\sigma}{\sigma}}(1-\alpha)+1-a\right)} .
\end{aligned}
$$

For $\sigma>1, \lim _{l \rightarrow 0} G(l)=0$ and $\lim _{l \rightarrow \infty} G(l)=+\infty$. Since $G(l)$ is a continuous function, there exists at least one equilibrium value of $l$ such that $G(l)$ crosses the positive value $n_{L} z$.

We now show that, for $\sigma>1, G^{\prime}(l)>0$ whenever $G(l)>0$. Therefore the equilibrium level $l$ satisfying (29) must be unique. Computing $G^{\prime}(l)$, rearranging some terms, using (1), (2) and (8), we can write:

$$
\begin{aligned}
G^{\prime}(l) & =\frac{1}{l \sigma}\left\{[\sigma-s](1-a) A\left(a n_{H}^{\frac{\sigma-1}{\sigma}} l^{\frac{(\sigma-1)^{2}}{\sigma}}+(1-a) l^{\sigma-1}\right)^{\frac{1}{\sigma-1}}\right. \\
& \left.-\frac{(1-a) b n_{L}}{\left(a n_{H}^{\frac{\sigma-1}{\sigma}} l^{\frac{1-\sigma}{\sigma}}(1-\alpha)+1-a\right)} \frac{s(1-\alpha)(\sigma-1)}{1-\alpha s}\right\} .
\end{aligned}
$$


Note that $\left(a n_{H}^{\frac{\sigma-1}{\sigma}} l^{\frac{(\sigma-1)^{2}}{\sigma}}+(1-a) l^{\sigma-1}\right)^{\frac{1}{\sigma-1}}>\frac{b n_{L}}{\left(a n_{H}^{\frac{\sigma-1}{\sigma}} l^{\frac{1-\sigma}{\sigma}}(1-\alpha)+1-a\right)}$ when $G(l)>0$.

Note also that $[\sigma-s]>\frac{s(1-\alpha)(\sigma-1)}{1-\alpha s}$, since $\frac{\sigma-s}{\sigma-1}>1>\frac{s-s \alpha}{1-\alpha s}$. Therefore $G^{\prime}(l)>0$ whenever $G(l)>0$.

Now we need to ensure the existence of unemployment of low skilled workers at equilibrium with $l<n_{L}$. Since $G(l)$, whenever positive, is increasing in $l$ and at equilibrium $G(l)=n_{L} z$, we obtain that $l<n_{L}$ as long as $G\left(n_{L}\right)>n_{L} z$. Since $G$ is increasing in $A$, the latter is ensured by considering that the parameter $A$ of total factor productivity is such that:

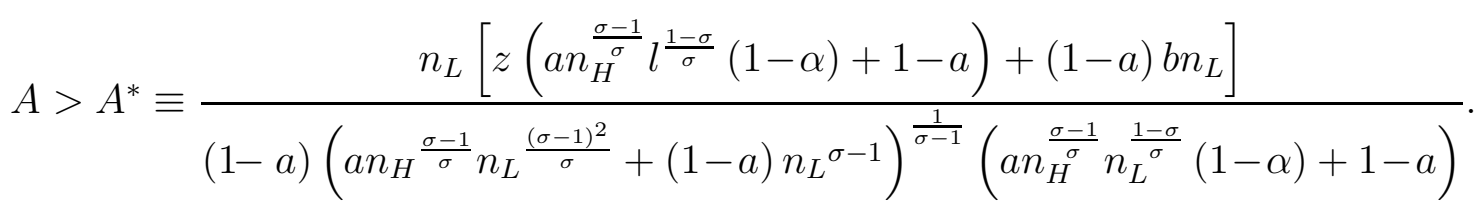

\section{Appendix II}

\section{The $G E R W$ and $M P L$ schedules}

We now show that, at the general equilibrium level, the schedule of $G E R W$ (given as $\left.\frac{z n_{L}}{l}+\frac{b n_{L}}{l \mu}\right)$ is steeper, with respect to $l$, than the $M P L$ schedule (given as $\left.\left[f(x)-f^{\prime}(x) x\right]\right)$. In order to do that let us compute the respective elasticities:

$$
\begin{aligned}
\varepsilon_{G E R W, l} & \equiv \frac{d G E R W}{d l} \frac{l}{G E R W}=-z \frac{n_{L}}{l^{2}} \frac{l}{G E R W}-\frac{b n_{L}}{l^{2} \mu(x)}\left(1-\varepsilon_{\mu, x}\right) \frac{l}{G E R W} \\
& =-\frac{n_{L}}{l^{2}} \frac{l}{G E R W}\left\{z+\frac{b}{\mu}\left(1-\varepsilon_{\mu, x}\right)\right\} \\
& =-\frac{1}{z+\frac{b}{\mu}}\left\{z+\frac{b}{\mu}\left(1-\varepsilon_{\mu, x}\right)\right\}
\end{aligned}
$$

As $z+\frac{b}{\mu}=A\left[f(x)-f^{\prime}(x) x\right] \frac{l}{n_{L}}$ at equilibrium with $G E R W=M P L$, and using (12) and (6), we obtain

$$
\begin{aligned}
\varepsilon_{G E R W, l} & =-\frac{1}{A\left[f(x)-f^{\prime}(x) x\right] \frac{l}{n_{L}}}\left\{A\left[f(x)-f^{\prime}(x) x\right] \frac{l}{n_{L}}-\frac{b}{\mu}+\frac{b}{\mu}\left(1-\varepsilon_{\mu, x}\right)\right\} \\
& =-\frac{A\left[f(x)-f^{\prime}(x) x\right] \frac{l}{n_{L}}-\frac{b}{\mu} \varepsilon_{\mu, x}}{A\left[f(x)-f^{\prime}(x) x\right] \frac{l}{n_{L}}} \\
& -\frac{A\left[f(x)-f^{\prime}(x) x\right] \frac{l}{n_{L}}-\tau A\left[f(x)-f^{\prime}(x) x\right] \frac{l}{n_{L}} \varepsilon_{\mu, x}}{A\left[f(x)-f^{\prime}(x) x\right] \frac{l}{n_{L}}} \\
& =-\left\{1-\tau \varepsilon_{\mu, x}\right\}=-\left\{1-\tau \frac{s(1-\alpha)}{1-\alpha s} \frac{\sigma-1}{\sigma}\right\}
\end{aligned}
$$




$$
\varepsilon_{M P L, l}=-\frac{s}{\sigma}
$$

The $G E R W$ and $M P L$ schedules are both negatively sloped and the former is steeper than the latter if $-\varepsilon_{G E R W, l}>-\varepsilon_{M P L, l}$. This condition can be written as $(\sigma-s)(1-\alpha s)>\tau^{L} s(1-\alpha)(\sigma-1)$, which is verified as $(\sigma-s)>(\sigma-1)>0$ and $(1-\alpha s)>\tau^{L}(s-\alpha s)$.

\section{Appendix III - The impact from changing the ben- efit policy on low skilled workers employment and income}

In this appendix we derive the expressions for the changes in employment and in income of low skilled workers resulting from changing the social benefit and the unemployment insurance.

From (13), i.e., from $A\left[f-f^{\prime} x\right] l=z n_{L}+b \frac{n_{L}}{\mu}$, we can compute the effect from changing $b$ on $l$ :

$$
\begin{aligned}
& A\left[f^{\prime}-f^{\prime}-f^{\prime \prime} x\right] l \frac{d x}{d b}+A\left[f-f^{\prime} x\right] \frac{d l}{d b}=\frac{n_{L}}{\mu}-\frac{n_{L}}{\mu^{2}} b \frac{d \mu}{d x} \frac{d x}{d b} \\
& -A f^{\prime \prime} x l \frac{d x}{d l} \frac{d l}{d b}+A\left[f-f^{\prime} x\right] \frac{d l}{d b}=\frac{n_{L}}{\mu}-\frac{n_{L}}{\mu^{2}} b \frac{d \mu}{d x} \frac{d x}{d l} \frac{d l}{d b} \\
& -A f^{\prime \prime} x l\left(-\frac{x}{l}\right) \frac{d l}{d b}+A\left[f-f^{\prime} x\right] \frac{d l}{d b}=\frac{n_{L}}{\mu}-\frac{n_{L}}{\mu x} b \varepsilon_{\mu, x}\left(-\frac{x}{l}\right) \frac{d l}{d b} \\
& A f^{\prime \prime} x x \frac{d l}{d b}+A\left[f-f^{\prime} x\right] \frac{d l}{d b}=\frac{n_{L}}{\mu}+\frac{n_{L}}{\mu} \frac{b}{l} \frac{s(\sigma-1)(1-\alpha)}{\sigma(1-\alpha s)} \frac{d l}{d b}
\end{aligned}
$$

where we have used the definition of skill intensity $x \equiv h / l$ and of the elasticity of the wage mark-up with respect to skill intensity (8). Using (12) we can substitute $b n_{L} / \mu$ in the above expression and simplifying, by means of (1) and (2) we have:

$$
\begin{aligned}
& A \frac{f^{\prime \prime} x}{f^{\prime}} \frac{f^{\prime} x}{f} \frac{d l}{d b}+A\left[1-\frac{f^{\prime} x}{f}\right] \frac{d l}{d b}=\frac{n_{L}}{\mu} \frac{1}{f}+\tau^{L} l A\left[1-\frac{f^{\prime} x}{f}\right] \frac{1}{l} \frac{s(\sigma-1)(1-\alpha)}{\sigma(1-\alpha s)} \frac{d l}{d b} \\
& -\frac{1-s}{\sigma} s \frac{d l}{d b}+(1-s) \frac{d l}{d b}=\frac{n_{L}}{\mu} \frac{1}{A f}+\tau^{L}(1-s) \frac{s(\sigma-1)(1-\alpha)}{\sigma(1-\alpha s)} \frac{d l}{d b} \\
& \frac{d l}{d b}\left[\frac{-s(1-\alpha s)+\sigma(1-\alpha s)-\tau^{L} s(\sigma-1)(1-\alpha)}{\sigma(1-\alpha s)}\right]=\frac{n_{L}}{\mu} \frac{1}{A f(1-s)}
\end{aligned}
$$

Finally, since $M P L=A f(1-s)$, we obtain (15):

$$
\begin{aligned}
& \frac{d l}{d b}=\frac{n_{L}}{w^{L}} \frac{\sigma(1-\alpha s)}{D} \\
& \text { with } D \equiv \sigma\left[(1-\alpha s)-\tau^{L} s(1-\alpha)\right]-s\left[(1-\alpha s)-\tau^{L}(1-\alpha)\right]
\end{aligned}
$$


The effect of $z$ on $l$ is obtained similarly from (13), using (8) for the elasticity of the mark-up, (12) for $b n_{L} / \mu$ and simplifying by means of (1) and (2):

$$
\begin{aligned}
& A\left[f^{\prime}-f^{\prime}-f^{\prime \prime} x\right] l \frac{d x}{d z}+A\left[f-f^{\prime} x\right] \frac{d l}{d z}=n_{L}-\frac{n_{L}}{\mu^{2}} b \frac{d \mu}{d x} \frac{d x}{d z} \\
& -A f^{\prime \prime} x l \frac{d x}{d l} \frac{d l}{d z}+A\left[f-f^{\prime} x\right] \frac{d l}{d z}=n_{L}-\frac{n_{L}}{\mu^{2}} b \frac{d \mu}{d x} \frac{d x}{d l} \frac{d l}{d z} \\
& -A f^{\prime \prime} x l\left(-\frac{x}{l}\right) \frac{d l}{d z}+A\left[f-f^{\prime} x\right] \frac{d l}{d z}=n_{L}-\frac{n_{L}}{\mu x} b \varepsilon_{\mu, x}\left(-\frac{x}{l}\right) \frac{d l}{d z} \\
& A f^{\prime \prime} x x \frac{d l}{d z}+A\left[f-f^{\prime} x\right] \frac{d l}{d z}=n_{L}+\frac{n_{L}}{\mu} \frac{b}{l} \frac{s(\sigma-1)(1-\alpha)}{\sigma(1-\alpha s)} \frac{d l}{d z} \\
& A \frac{f^{\prime \prime} x}{f^{\prime}} \frac{f^{\prime} x}{f} \frac{d l}{d z}+A\left[1-\frac{f^{\prime} x}{f}\right] \frac{d l}{d z}=\frac{n_{L}}{f}+\tau^{L} A\left[1-\frac{f^{\prime} x}{f}\right] \frac{s(\sigma-1)(1-\alpha)}{\sigma(1-\alpha s)} \frac{d l}{d z} \\
& -\frac{s}{\sigma} \frac{d l}{d z}+\frac{d l}{d z}=\frac{n_{L}}{A f(1-s)}+\tau^{L} \frac{s(\sigma-1)(1-\alpha)}{\sigma(1-\alpha s)} \frac{d l}{d z} \\
& \frac{d l}{d z}\left[\frac{\sigma\left[(1-\alpha s)-\tau^{L} s(1-\alpha)\right]-s\left[(1-\alpha s)-\tau^{L}(1-\alpha)\right]}{\sigma(1-\alpha s)}\right]=\frac{n_{L}}{M P L}
\end{aligned}
$$

i.e., (16) follows:

$$
\frac{d l}{d z}=\mu \frac{n_{L}}{w^{L}} \frac{\sigma(1-\alpha s)}{D}
$$

Before deriving the impact of $b$ and $z$ on $y^{l}$, which is given by (17)

$$
y^{l}=w^{L}-z\left(\frac{n_{L}}{l}-1\right)+b\left(1-\frac{n_{L}}{l}\right),
$$

note that using $z+q=z n_{L} / l$ from (10) and $\tau^{L}$ from (12) in (4) we have

$$
M P L=\frac{z n_{L} / l}{1-\tau^{L}}
$$

i.e., $z=A\left[f-f^{\prime} x\right]\left(1-\tau^{L}\right) /\left(n_{L} / l\right)$ and, from (12), we have $b=\mu A\left[f-f^{\prime} x\right] \tau^{L} /\left(n_{L} / l\right)$. Therefore:

$$
\frac{z}{b}=\frac{\left(1-\tau^{L}\right)}{\mu \tau^{L}}=\frac{(1-s)\left(1-\tau^{L}\right)}{(1-\alpha s) \tau^{L}}
$$

From (17), using (3) for $w^{L},(12)$ for $w^{L} l / b n_{L}$, the definition of the unemployment rate $\gamma \equiv\left(n_{L}-l\right) / n_{L}, \varepsilon_{x, b}=-\varepsilon_{l, b}$ and (31) for $z / b$, we have

$$
\begin{aligned}
\frac{d y^{l}}{d b} & =\mu \frac{d M P L}{d x} \frac{d x}{d b}+M P L \frac{d \mu}{d x} \frac{d x}{d b}+b \frac{n_{L}}{l^{2}} \frac{d l}{d b}+z \frac{n_{L}}{l^{2}} \frac{d l}{d b}-\left(\frac{n_{L}}{l}-1\right) \\
& =\frac{\mu M P L}{x}\left(\varepsilon_{M P L, x}+\varepsilon_{\mu, x}\right) \frac{d x}{d b}+\frac{n_{L}}{l} \varepsilon_{l, b}+z \frac{n_{L}}{l b} \varepsilon_{l, b}-\left(\frac{n_{L}}{l}-1\right) \\
& =\frac{n_{L}}{l}\left[\frac{w^{L} l}{b n_{L}}\left(\varepsilon_{M P L, x}+\varepsilon_{\mu, x}\right) \varepsilon_{x, b}+\varepsilon_{l, b}+\frac{z}{b} \varepsilon_{l, b}-\left(1-\frac{l}{n_{L}}\right)\right] \\
& =\frac{1}{1-\gamma}\left[\left(-\frac{1}{\tau^{L}}\left(\varepsilon_{M P L, x}+\varepsilon_{\mu, x}\right)+1+\frac{z}{b}\right) \varepsilon_{l, b}-\gamma\right]
\end{aligned}
$$


i.e.,

$$
\frac{d y^{l}}{d b}=\frac{1}{1-\gamma}\left[\left(1+\frac{(1-s)\left(1-\tau^{L}\right)}{(1-\alpha s) \tau^{L}}-\frac{1}{\tau^{L}}\left(\varepsilon_{M P L, x}+\varepsilon_{\mu, x}\right)\right) \varepsilon_{l, b}-\gamma\right]
$$

Substituting the expressions for the elasticities (8) and (15) and using the social benefit budget constraint (11) we obtain

$$
\begin{aligned}
\frac{d y^{l}}{d b} & =\frac{1}{1-\gamma}\left[\left(1+\frac{(1-s)\left(1-\tau^{L}\right)}{(1-\alpha s) \tau^{L}}-\frac{1}{\tau^{L}} \frac{s}{\sigma} \frac{\sigma(1-\alpha)+\alpha(1-s)}{1-\alpha s}\right) \varepsilon_{l, b}-\gamma\right] \\
& =\frac{1}{1-\gamma}\left[\frac{\sigma\left[\tau^{L}(1-\alpha s)+(1-s)\left(1-\tau^{L}\right)-s(1-\alpha)\right]-s \alpha(1-s)}{\sigma \tau^{L}(1-\alpha s)} \varepsilon_{l, b}-\gamma\right] \\
& =\frac{1}{1-\gamma}\left[\frac{\sigma\left[(1-s)-s(1-\alpha)\left(1-\tau^{L}\right)\right]-s \alpha(1-s)}{\tau^{L} D} \frac{b n_{L}}{l w^{L}}-\gamma\right] \\
& =\frac{1}{1-\gamma}\left[\frac{\sigma\left[(1-s)-s(1-\alpha)\left(1-\tau^{L}\right)\right]-s \alpha(1-s)}{\tau^{L} D} \tau^{L}-\gamma\right]
\end{aligned}
$$

and therefore we have (21):

$$
\begin{aligned}
& \frac{d y^{l}}{d b}=\frac{1}{1-\gamma}\left[\frac{B}{D}-\gamma\right] \\
& \text { with } B \equiv \sigma\left[(1-s)-s(1-\alpha)\left(1-\tau^{L}\right)\right]-s \alpha(1-s)
\end{aligned}
$$

The impact of changing the unemployment subsidy on low skilled income is also obtained from (17) using (3) for $w^{L}$, (30) for $M P L l / z n_{L}$, (1), the definition of the unemployment rate $\gamma \equiv\left(n_{L}-l\right) / n_{L}, \varepsilon_{x, b}=-\varepsilon_{l, b}$ and (31) for $b / z$, we have

$$
\begin{aligned}
\frac{d y^{l}}{d z} & =\mu \frac{d M P L}{d x} \frac{d x}{d z}+M P L \frac{d \mu}{d x} \frac{d x}{d z}+b \frac{n_{L}}{l^{2}} \frac{d l}{d z}+z \frac{n_{L}}{l^{2}} \frac{d l}{d z}-\left(\frac{n_{L}}{l}-1\right) \\
& =\frac{\mu M P L}{x}\left(\varepsilon_{M P L, x}+\varepsilon_{\mu, x}\right) \frac{d x}{d z}+b \frac{n_{L}}{l z} \varepsilon_{l, z}+\frac{n_{L}}{l} \varepsilon_{l, z}-\left(\frac{n_{L}}{l}-1\right) \\
& =\frac{n_{L}}{l}\left[\frac{\mu M P L l}{z n_{L}}\left(\varepsilon_{M P L, x}+\varepsilon_{\mu, x}\right) \varepsilon_{x, z}+\frac{b}{z} \varepsilon_{l, z}+\varepsilon_{l, z}-\left(1-\frac{l}{n_{L}}\right)\right] \\
& =\frac{1}{1-\gamma}\left[\left(1+\frac{b}{z}-\frac{\mu}{1-\tau^{L}}\left(\varepsilon_{M P L, x}+\varepsilon_{\mu, x}\right)\right) \varepsilon_{l, z}-\gamma\right] \\
& =\frac{1}{1-\gamma}\left[\left(1+\frac{\mu \tau^{L}}{1-\tau^{L}}-\frac{\mu}{1-\tau^{L}}\left(\varepsilon_{M P L, x}+\varepsilon_{\mu, x}\right)\right) \varepsilon_{l, z}-\gamma\right]
\end{aligned}
$$

Substituting the expressions for the elasticities of $M P L$ and $\mu$ (8), the wage markup (5) and the effect of $z$ on employment (16), we obtain 


$$
\begin{aligned}
\frac{d y^{l}}{d z} & =\frac{1}{1-\gamma}\left[\left(1+\frac{\mu}{1-\tau^{L}}\left[\tau^{L}-\frac{s}{\sigma} \frac{\sigma(1-\alpha)+\alpha(1-s)}{1-\alpha s}\right]\right) \varepsilon_{l, z}-\gamma\right] \\
& =\frac{1}{1-\gamma}\left[\left(1+\frac{\mu}{1-\tau^{L}}\left[\frac{\tau^{L} \sigma(1-\alpha s)-s \sigma(1-\alpha)-s \alpha(1-s)}{\sigma(1-\alpha s)}\right]\right) \varepsilon_{l, z}-\gamma\right] \\
& =\frac{1}{1-\gamma}\left[\frac{\sigma\left[(1-s)-s(1-\alpha)\left(1-\tau^{L}\right)\right]-s \alpha(1-s)}{\sigma(1-s)\left(1-\tau^{L}\right)} \varepsilon_{l, z}-\gamma\right] \\
& =\frac{1}{1-\gamma}\left[\frac{B}{\sigma(1-s)\left(1-\tau^{L}\right)} \frac{z}{l} \mu \frac{n_{L}}{w^{L}} \frac{\sigma(1-\alpha s)}{D}-\gamma\right] \\
& =\frac{1}{1-\gamma}\left[\mu \frac{B}{D} \frac{z}{l} \frac{n_{L}}{w^{L}} \frac{\mu}{1-\tau^{L}}-\gamma\right]
\end{aligned}
$$

Using the definition of the low skilled wage (3) and simplifying by means of (30), we finally obtain (22):

$$
\begin{aligned}
\frac{d y^{l}}{d z} & =\frac{1}{1-\gamma}\left[\mu \frac{B}{D} \frac{z n_{L}}{\mu M P L l} \frac{\mu}{1-\tau^{L}}-\gamma\right] \\
& =\frac{1}{1-\gamma}\left[\mu \frac{B}{D} \frac{z n_{L} / l}{\left(1-\tau^{L}\right) M P L}-\gamma\right] \\
& =\frac{1}{1-\gamma}\left[\mu \frac{B}{D}-\gamma\right]
\end{aligned}
$$

